\title{
ANALISIS PENGARUH TREN BUDAYA, BRAND AMBASSADOR DAN HARGA TERHADAP PURCHASE INTENTION
}

\author{
Francisca Triyana Resti Prastiwi \\ Universitas Merdeka Malang \\ francisca.resti95@gmail.com
}

\author{
Christina Sri Ratnaningsih \\ Universitas Merdeka Malang \\ christina.sri@unmer.ac.id
}

Irany Windhyastiti*

Universitas Merdeka Malang

irani.windhyastiti@unmer.ac.id

\author{
Umu Khouroh \\ Universitas Merdeka Malang \\ umu.khouroh@unmer.ac.ld
}

\section{Suggested Citation:}

Oktaviani, L., \& Sutopo. (2014). Analisis Pengaruh Brand Image,Kualitas Produk dan Harga Terhadap Minat Beli Produk Mie Instan Supermie. Diponegoro Journal of Management, 3(4), 1-14.

\begin{abstract}
:
This research aims to find out how the influence of cultural trends, brand ambassadors and prices on the purchase intention of Korean instant noodles. The population in this study is Twitter users, members of Korean Pop fans who idolize the ambassador brand from the Korean band "Super Junior" who consume instant noodles. The number of samples taken in this study used the Lemeshow formula as much 100 respondents. The sampling technique uses non-probability techniques, namely incidental sampling techniques. The analytical tool used in this study is Multiple Regression Analysis. The results show that: 1) the culture trend of Korean Wave variable does not have a significant effect on purchase intention, 2) the brand ambassador variable has a significant effect on purchase intention, and 3) the price variable has a significant effect on purchase intention
\end{abstract}

\section{Keywords Brand Ambassador, Price, Purchase Intention, Trend of Culture}

Abstrak:

Penelitian ini dilakukan untuk mengetahui bagaimana pengaruh tren budaya, brand ambassador dan harga terhadap purchase intention mie instan cita rasa Korea. Populasi dalam penelitian ini adalah pengguna twitter tergabung sebagai penggemar Korean Pop yang mengidolakan brand smbassador yaitu dari grup band Korea "Super Junior" yang mengkonsumsi mie instan. Jumlah sampel yang diambil dalam penelitian ini menggunakan rumus Lemeshow sebanyak 100 responden. Teknik pengambilan sampel menggunakan teknik non probability yakni teknik incidental sampling atau teknik penentuan sampel berdasarkan kebetulan berinteraksi dengan peneliti dan cocok sebagai sumber data. Alat analisa yang digunakan adalah Analisa Regresi Berganda dan hasil penelitian menunjukkan bahwa:, 1) variabel tren budaya Korean Wave tidak mempunyai pengaruh yang signifikan terhadap purchase intention ,2) variabel brand ambassador mempunyai pengaruh yang signifikan terhadap purchase intention, dan 3) variabel harga mempunyai pengaruh yang signifikan terhadap purchase intention.

Kata Kunci: Brand Ambassador, Harga, Purchase Intention, Tren Budaya

JEL Classification: L82; M31 


\section{Pendahuluan}

Berdasar data World Instant Noodles Association (WINA), Indonesia menempati urutan ke-2 permintaan mie instan di dunia dengan jumlah mencapai 12,54 Milyar di tahun 2018 ("Global Demand for Instant Noodles Estimated," 2019). Besarnya permintaan mie instan di Indonesia mendorong perusahaan produsen mie instan bersaing merebut pasar yang salah satunya dilakukan dengan mengeluarkan berbagai varian baru. Varian mie instan terbaru salah satunya adalah mie dengan cita rasa Korea. Munculnya mie dengan cita rasa Korea ini dipengaruhi oleh tren budaya pop Korea Selatan yang menyerbu berbagai negara, termasuk di Indonesia. Tren budaya ini dikenal dengan istilah Hallyu (Korean Wave).

Penelitian Kim (2014) menjelaskan efek gelombang Korea di negara Indonesia yang memperlihatkan bahwa skenario dan karakter drama Korea berhasil menyentuh emosi masyarakat Indonesia. Sentuhan emosional, simpati, dan empati terssebut mampu menghasilkan citra positif Korea. Hasil penelitian tersebut menunjukkan bahwa sikap konsumen terhadap elemen budaya negara asing berdampak pada citra mereka tentang negara asal (Kim, Do Cho, \& Ok Jung, 2014). Hasil penelitian Kim (2014) sangat relevan jika dilihat dari banyaknya masyarakat Indonesia yang tertarik dengan budaya Korea mulai dari industri hiburan, industri fashion sampai industri makanan.

Hasil penelitian Son (2016) menunjukkan bahwa Korean Wave mempunyai pengaruh postif terhadap country image yang kemudian berdampak terhadap purchase intention pembelian kosmetik di Korea (Son \& Kijboonchoo, 2016). Penelitian pada produk kosmetik Korea, juga menunjukkan hasil bahwa budaya populer mempunyai pengaruh signifikan terhadap sikap dan minat beli konsumen di Indonesia terhadap produk kosmetik Korea (Sumiati, 2020). Selanjutnya karena semakin kentalnya nuansa Korea di industri hiburan yang ditunjukkan dengan semakin banyaknya drama dan musik pop Korea yang populer di Indonesia, maka salah satu perusahaan produsen Mie Sedaap memilih "Choi Siwon" anggota Boygrup "Super Junior" sebagai Brand Ambassador Mie Sedaap Korean Spicy Chicken.

Hasil penelitian Saputro (2018) menunjukkan bahwa brand ambassador anak presiden "Gibran dan Kaesang" mampu membentuk brand identity yang selanjutnya berdampak pada purchase intention produk makanan Markobar (Saputro et al., 2018). Penelitian pada produk makanan Bandung Kunafe Cake juga menunjukkan bahwa brand ambassador artis "Irfan Hakim dan Ananda" Omesh mempunyai pengaruh yang signifikan terhadap minat beli (Mardiani \& Wardhana, 2018). Selain faktor tren budaya dan kekuatan brand ambassador dalam mempengaruhi minat beli, faktor lain menurut yang juga mempengaruhi minat beli mie instan adalah citra merek, kualitas produk dan harga (Oktaviani \& Sutopo, 2014).

Faktor harga menjadi fenomena yang menarik karena "Mie Sedaap Korean Spicy Chicken" menawarkan harga cukup murah hanya sekitar Rp. 2.500 sd Rp.2.900 per bungkusnya. Sementara harga mie instan cita rasa Korea "Samyang" yang sebelumnya telah dikenal masyarakat dibandrol dengan harga yang jauh lebih tinggi sekitar Rp.16.000 sd Rp.22.000 per bungkus. Berdasar uraian tersebut di atas, maka penelitian ini dilakukan dengan menggabungkan beberapa variabel penelitian di atas yaitu variabel tren budaya, brand ambassador dan harga dengan tujuan untuk mengetahui bagaimana pengaruh tren budaya, brand ambassador dan harga terhadap purchase intention mie instan cita rasa Korea.

\section{Kajian Literatur}

\section{Pengaruh Tren Budaya Terhadap Purchase Intention}

Budaya merupakan suatu hal yang berhubungan dengan susunan masyarakat dan dihasilkan dari interaksi atau hubungan masyarakat. Dalam budaya secara umum terdapat kebiasaan (habit), nilai (value) dan pola hidup (lifestyle) manusia yang berbeda antara suatu masyarakat dengan masyarakat yang lain. Menurut Prasetya (2004) "kebudayaan meliputi sikap dan hasil sikap manusia yang teratur oleh tatanan sikap yang dapat diperoleh dengan belajar dimana semuanya tersusun dalam kehidupan masyarakat" (Prasetya \& Tri., 2004). Peningkatan industri dan kapitalisme menyebabkan budaya menjadi suatu komoditi yang dapat diperjualbelikan. Industri budaya muncul menjadi suatu hal yang menarik bagi masyarakat dan mampu menghasilkan keuntungan. Perkembangan kebudayaan tersebut tidak terlepas dari peran media baik sebagai sarana komunikasi, alat pengukur informasi maupun hiburan. Secara umum perkembangan kebudayaan ini diartikan sebagai globalisasi kebudayaan yang kemudian mengalami perkembangan yang sangat cepat. Kecepatan perkembangan globalisasi kebudayaan dipengaruhi oleh kecepatan dan kemudahan dalam memperoleh akses informasi yang menjadi hal krusial dalam masyarakat (Koentjaraningrat, 1999). Salah satu budaya yang menjadi tren di Indonesia adalah budaya Korea yang dikenal dengan Korean Wave. Penelitian Kim (2014) menjelaskan efek gelombang Korea di negara Indonesia yang memperlihatkan bahwa skenario dan karakter drama Korea berhasil menyentuh emosi masyarakat Indonesia. Sentuhan emosional, simpati, dan empati terssebut mampu 
menghasilkan citra positif Korea. Hasil penelitian tersebut menunjukkan bahwa sikap konsumen terhadap elemen budaya negara asing berdampak pada citra mereka tentang negara asal (Kim, Do Cho, \& Ok Jung, 2014). Selanjutnya hasil penelitian Son (2016) menunjukkan bahwa Korean Wave mempunyai pengaruh postif terhadap country image yang kemudian berdampak terhadap purchase intention pembelian kosmetik di Korea (Son \& Kijboonchoo, 2016). Sejalan dengan penelitian Son, hasil penelitian Zenas Tjoe memperlihatkan hasil bahwa Korean Wave, Ethnocentrism, dan Country-of-Origin Image secara signifikan mempunyai pengaruh signifikan terhadap minat pembelian produk Korea di Indonesia (Zenas Tjoe, 2016). Hasil penelitian pada interface online store juga menunjukkan bahwa faktor budaya mempunyai pengaruh terhadap perilaku repeat purchase intention (Qhusna, 2018). Begitu juga halnya dengan penelitian Sumiati (2020) yang bertujuan untuk mengetahui bagaimana pengaruh etnosentrisme dan budaya populer Korean Wave terhadap sikap dan minat beli konsumen di Indonesia terhadap produk kosmetik Korea, memperlihatkan hasil bahwa etnosentrisme dan budaya populer mempunyai pengaruh signifikan terhadap sikap dan minat beli konsumen (Sumiati, 2020). Berdasar uraian beberapa hasil penelitian tersebut di atas, maka hipotesis pertama dalam penelitian ini adalah sebagai berikut:

H1: Trend budaya mempunyai pengaruh signifikan terhadap purchase intention

\section{Pengaruh Brand Ambassador Terhadap Purchase Intention}

Brand ambassador adalah seseorang atau sekelompok orang yang bekerja pada sebuah organisasi atau perusahaan yang mendapat tugas untuk berperan dalam mempromosikan suatu merek produk atau jasa. Brand ambassador diberi tugas untuk menunjukkan identitas perusahaan dalam penampilan atau performance, sikap, nilai dan etika. Aspek kunci dari brand ambassador terdapat pada keterampilan mereka untuk menerapkan strategi promosi yang dapat mendorong pelanggan untuk membeli suatu produk lebih frekuensi atau volume yang lebih banyak lagi. Penunjukkan brand ambassador biasanya didasarkan pada citra positif yang dimilikinya sehingga dapat mewakili citra produk secara keseluruhan. Dimana diharapkan dengan citra positif dari brand ambassador tersebut mampu meningkatkan minat beli konsumen terhadap produk tertentu. Hasil penelitian Saputro (2018) menunjukkan bahwa brand ambassador "Gibran daan Kaesang" mampu membentuk brand identity yang selanjutnya berdampak pada purchase intention produk makanan Markobar (Saputro et al., 2018). Sejalan dengan hasil penelitian tersebut, hasil penelitian Sen Cece (2015) juga menunjukkan brand ambassador mempunyai pengaruh yang signifikan terhadap minat beli sepatu merek Macbeth di Sogo Galaxy (Sen Cece, 2015). Begitu juga halnya dengan penelitian Ningrum (2016) yang memperlihatkan hasil bahwa brand ambassador artis "Syahnaz" mempunyai pengaruh yang signifikan terhadap minat beli terhadap produk perawatan kecantikan MD Clinic by Lazeta (Ningrum, 2016). Penelitian pada produk makanan Bandung Kunafe Cake juga menunjukkan bahwa brand ambassador artis "Irfan Hakim dan Ananda Omesh" mempunyai pengaruh yang signifikan terhadap minat beli (Mardiani \& Wardhana, 2018). Berdasar uraian beberapa hasil penelitian di atas, maka hipotesis kedua dalam penelitian ini adalah sebagai berikut:

H2: Brand ambassador mempunyai signifikan terhadap purchase intention

\section{Pengaruh Harga Terhadap Purchase Intention}

Harga merupakan hal yang di perhatikan konsumen saat melakukan pembelian. Harga adalah jumlah sesuatu yang memiliki nilai (value) pada umumnya dalam bentuk uang yang harus dikorbankan untuk mendapatkan suatu produk (Suparyanto \& Rosad, 2015). Faktor harga menjadi fenomena yang menarik dalam industri mie instan karena "Mie Sedaap Korean Spicy Chicken" menawarkan harga cukup murah hanya sekitar Rp. 2.500 sd Rp.2.900 per bungkusnya. Sementara harga mie instan cita rasa Korea "Samyang" yang sebelumnya telah dikenal masyarakat dibandrol dengan harga yang jauh lebih tinggi sekitar Rp.16.000 sd Rp.22.000 per bungkus. Hasil penelitian Oktaviani (2014) menunjukkan bahwa harga mempengaruhi minta beli mie instan "Supermie" (Oktaviani \& Sutopo, 2014). Hasil ini sejalan dengan hasil penelitian Intan Pratiwi (2018) yang memperlihatkan bahwa harga mempunyai pengaruh terhadap keputusan pembelian Luwak White Koffie (Intan Pratiwi, 2018). Berdasar uraian beberapa hasil penelitian di atas, maka hipotesis ketiga adalam penelitian ini adalah sebagai berikut:

H3: Harga mempunyai pengaruh signifikan terhadap purchase intention

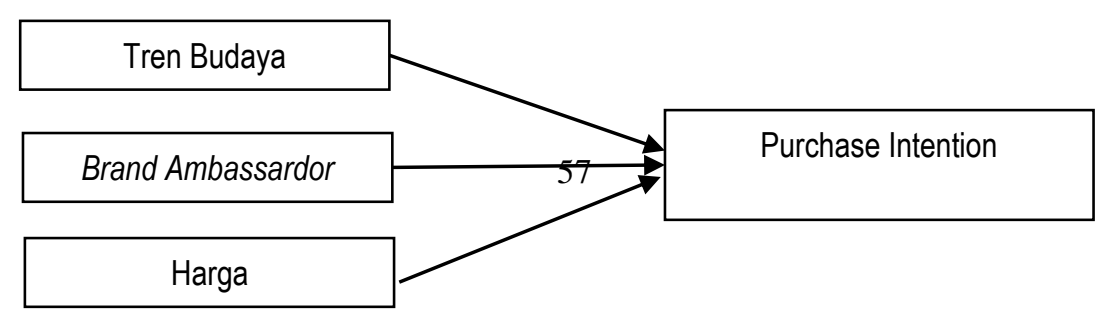




\section{Metode Penelitian}

Populasi dalam penelitian ini adalah pengguna twitter tergabung sebagai penggemar Korean Pop yang mengidolakan brand smbassador yaitu dari grup band Korea "Super Junior" yang mengkonsumsi mie instan. Jumlah populasi tidak diketahui dan dapat di katakan dalam kategori tak terhingga. Teknik pengambilan sampel menggunakan teknik non probability yakni teknik incidental sampling atau teknik penentuan sampel berdasarkan kebetulan berinteraksi dengan peneliti dan cocok sebagai sumber data. Jumlah Sampel yang diambil dalam penelitian ini menggunakan Rumus Lemeshow, dengan pertimbangan karena jumlah populasi tidak diketahui atau tidak terhingga. Berdasarkan rumus tersebut maka $n$ yang didapatkan adalah 96,04 (dibulatkan 100) sehingga pada penelitian ini diambil sampel sejumlah 100 orang.

Alat analisis yang digunakan adalah Analisis Regresi Berganda dengan variabel dan indikator penelitian sebagaimana dalam tabel 1 di bawah ini.

Tabel 1

Definisi Operasional dan Indikator Variabel

\begin{tabular}{|c|c|c|}
\hline Variabel & Definisi & Indikator \\
\hline $\begin{array}{l}\text { Tren budaya Korean } \\
\text { Wave (X1) }\end{array}$ & $\begin{array}{l}\text { Tren budaya Korean Wave adalah } \\
\text { fenomena budaya popular asal Korea } \\
\text { Selatan yang cukup berpengaruh di } \\
\text { Indonesia dimana budaya juga dapat } \\
\text { mempengaruhi minat beli. }\end{array}$ & $\begin{array}{ll}\text { 1. } & \text { Mengenal tentang Korean Wave } \\
\text { 2. } & \text { Menyukai Korean Wave } \\
\text { 3. Tertarik pada Korean Wave } \\
\text { 4. Mempunyai pengaruh dalam } \\
\text { kegiatan sehari hari }\end{array}$ \\
\hline Brand ambassador (X2) & $\begin{array}{l}\text { Brand ambassador adalah sesuatu yang } \\
\text { dilakukan perusahaan untuk } \\
\text { mempengaruhi konsumen dengan } \\
\text { menggunakan selebriti sebagai ikon } \\
\text { untuk memperkenalkan citra terbaik } \\
\text { dari produk yang mereka hasilkan }\end{array}$ & $\begin{array}{ll}\text { 1. } & \text { Kepopuleran } \\
\text { 2. } & \text { Kredibilitas } \\
\text { 3. } & \text { Daya Tarik } \\
\text { 4. } & \text { Kekuatan }\end{array}$ \\
\hline Harga $\left(X_{3}\right)$ & $\begin{array}{l}\text { Harga adalah sejumlah uang yang harus } \\
\text { dibayarkan konsumen untuk } \\
\text { memperoleh suatu produk (barang atau } \\
\text { jasa). }\end{array}$ & $\begin{array}{ll}\text { 1. } & \text { Kesesuaian harga } \\
\text { 2. } & \text { Diskon harga khusus } \\
\text { 3. } & \text { Harga yang di persepsikan }\end{array}$ \\
\hline Purchase Intention $(\mathrm{Y})$ & $\begin{array}{l}\text { Purchase Intention atau minat beli } \\
\text { konsumen adalah sikap konsumen yang } \\
\text { mencerminkan rencana pembelian } \\
\text { produk dengan merk tertentu. }\end{array}$ & $\begin{array}{ll}\text { 1. } & \text { Minat transaksional } \\
\text { 2. } & \text { Minat referensial } \\
\text { 3. } & \text { Minat preferensial } \\
\text { 4. } & \text { Minat eksploratif } \\
\end{array}$ \\
\hline
\end{tabular}

Hasil

Berdasarkan tabel 2 di bawah ini, dapat dilihat besarnya koefisien determinasi ( Adjusted R2 ) $=0,378$, artinya variabel brand ambassador, Korean Wave, dan harga mempengaruhi minat beli konsumen sebesar $37,8 \%$, sedangkan sisanya sebesar $62,2 \%$ dipengaruhi oleh variabel lain yang tidak di teliti dalam penelitian ini misalnya brand reputation atau citra merek, kualitas produk, serta ketersediaan barang di pasar dapat menjadi alternatif pertimbangan dalam menentukan minat beli. Hasil Uji $\mathrm{F}$ pada tabel 2, menunjukkan bahwa variabel trend budaya Korean Wave, brand ambassador dan harga mempunyai pengaruh signifikan secara simultan atau bersama-sama terhadap purchase intention (sig $\mathrm{F}=0,000$ ). Sedangkan hasil uji $\mathrm{t}$ menunjukkan bahwa:, 1 ) variabel Korean Wave (X1) tidak mempunyai pengaruh signifikan terhadap purchase intention (sig $t=0,316$ ), berarti hipotesis pertama ditolak, 2) variabel brand ambassador (X2) mempunyai pengaruh signifikan terhadap 
purchase intention (sig $t=0,021$ ), berarti hipotesis kedua diterima, dan 3) variabel harga $(X 3)$ mempunyai pengaruh signifikan terhadap purchase intention (sig $\mathrm{t}=0,000$ ), berarti hipotesis ketiga diterima.

Tabel 2

Hasil Analisis Statistik

\begin{tabular}{lllrr}
\multicolumn{1}{c}{ Variabel } & \multicolumn{1}{c}{ Keterangan } & Koefisien Regresi $(\mathrm{B})$ & thitung & Sig. \\
\hline $\mathrm{X}_{1}$ & Korean Wave & 0,100 & 1,008 & 0,316 \\
\hline $\mathrm{X}_{2}$ & Brand Ambassador & 0,305 & 2,349 & 0,021 \\
\hline $\mathrm{X}_{3}$ & Harga & 0,813 & 5,502 & 0,000 \\
\hline Konstanta & $-2,143$ & & & \\
$\mathrm{R}$ & 0,630 & & & \\
Adjusted $\mathrm{R}^{2}$ & 0,378 & & & \\
$\mathrm{~F}_{\text {hitung }}$ & 21,074 & & \\
Sig $\mathrm{F}$ & 0,000 & & \\
$\mathrm{~N}$ & 100 & & \\
Variabel terikat $=$ Purchase Intention $(\mathrm{Y})$ & & & \\
trabel $\quad=1,660$ & & & \\
$\mathrm{~F}_{\text {tabel }}=2,14$ & & &
\end{tabular}

Sumber : Data primer diolah, 2020

\section{Pembahasan}

Variabel Korean Wave (X1) tidak mempunyai pengaruh signifikan terhadap purchase intention mie instan cita rasa Korea. Hasil penelitian ini tidak sejalan dengan penelitian terdahulu yang di lakukan oleh Zenas Tjoe (2016), yang menunjukkan bahwa Korean Wave secara signifikan mempengaruhi minat beli konsumen terhadap produk kosmetik Korea di Indonesia. Hal ini membuktikan bahwa tren budaya asing tidak berpengaruh pada masyarakat Indonesia meskipun responden dalam penelitian ini adalah penggemar Korean Pop namun budaya Korea mempunyai pengaruh yang tidak signifikan terhadap minat beli mie instan. Perbedaan penelitian ini karena perbedaan produk, dimana pada penelitian Zenas Tjoe (2016) menggunakan produk kosmetik, sedangkan penelitian ini menggunakan produk makanan.

Variabel brand ambassador (X2) mempunyai pengaruh signifikan terhadap purchase intention mie instan cita rasa Korea. Hasil penelitian ini sejalan dengan penelitian terdahulu yang dilakukan oleh Sen Cece (2015), Ningrum (2016) dan Mardiana \& Wardhana (2018) yang menunjukkan bahwa brand ambassador mempunyai pengaruh yang signifikan terhadap minat beli sepatu merek Macbeth di Sogo Galaxy Surabaya (Sen Cece, 2015), produk perawatan kecantikan MD Clinic by Lazeta (Ningrum, 2016), serta Bandung Kunafe Cake (Mardiani \& Wardhana, 2018). Hal ini dapat di simpulkan bahwa pemilihan brand ambassador yang tepat yang memenuhi beberapa faktor seperti kepopulerannya, kredibilitas, kekuatan, serta daya tarik dapat menjadi bahan pertimbangan bagi konsumen dalam memutuskan membeli produk.

Variabel harga (X3) mempunyai pengaruh signifikan terhadap purchase intention. Hal ini sejalan dengan hasil penelitian Oktaviani (2014) yang menunjukkan bahwa harga mempengaruhi minta beli mie instan "Supermie". Hasil ini juga sejalan dengan hasil penelitian Intan Pratiwi (2018) yang memperlihatkan bahwa harga mempunyai yang pengaruh terhadap keputusan pembelian Luwak White Koffie (Intan Pratiwi, 2018). Dari besarnya nilai koefisien regresi menunjukkan variabel harga mempunyai pengaruh dominan terhadap purchase intention. Hal ini membuktikan bahwa harga menjadi pertimbangan utama masyarakat pada minat beli mie instan cita rasa Korea. Kesesuaian harga pada produk sangat perpengaruh bagi konsumen dalam menentukan produk yang akan di beli.

Dari uraian ketiga variabel independen di atas, masyarakat Indonesia khususnya penggemar Korean Pop yang ada di twitter mempunyai minat beli untuk produk mie karena harganya yang sesuai dan adanya ketertarikan dengan brand ambassador dari produk tersebut. Hal ini memperlihatkan bahwa perusahaan telah membuat kebijakan harga yang tepat, dimana harga dinilai sesuai dengan kualitas produk yang ditawarkan dan sesuai dengan daya beli target utama konsumennya. "Mie Sedaap Korean Spicy Chicken" menawarkan harga cukup murah hanya sekitar Rp. 2.500 sd Rp.2.900 per bungkusnya. Sementara harga mie instan cita rasa Korea "Samyang" yang sebelumnya telah dikenal masyarakat dibandrol dengan harga yang jauh lebih tinggi sekitar 
Rp.16.000 sd Rp.22.000 per bungkus. Sedangkan dari sisi brand ambassador, perusahaan telah melakukan pemilihan brand ambassador yang tepat sesuai dengan target konsumennya.

\section{Kesimpulan}

Berdasarkan hasil analisa data dapat disimpulkan: 1) Tren budaya yang ditunjukkan oleh Korean Wave tidak mempunyai pengaruh signifikan terhadap minat beli Mie Sedaap Korean Spicy Chicken di kalangan penggemar Korean Pop di media sosial twitter, 2) Brand ambassador mempunyai pengaruh yang signifikan terhadap minat beli Mie Sedaap Korean Spicy Chicken di kalangan penggemar Korean Pop di media sosial twitter, 3) Harga berpengaruh secara signifikan dan menjadi variabel yang paling berpengaruh terhadap minat beli Mie Sedaap Korean Spicy Chicken di kalangan penggemar Korean Pop di media sosial twitter.

\section{Daftar Pustaka}

Global Demand for Instant Noodles Estimated. (2019). Retrieved from World Instant Noodles Association (WINA) website: instantnoodles.org

Intan Pratiwi, R. (2018). Pengaruh Label Halal, Kualitas Produk, Brand Image, Harga Terhadap Keputusan Pembelian Produk (Studi Kasus Pada Konsumen Produk Luwak White Koffie). Universitas Islam Negeri Sunan Kalijaga.

Kim, D., Do Cho, S., \& Ok Jung, G. (2014). Wave of Home Culture and MNC Performance: The Korean Wave (Hallyu). International Marketing in Rapidly Changing Environments ., 24, 193-216.

Koentjaraningrat. (1999). Pengantar IImu Antropologi. Jakarta: PT Rineka Cipta.

Mardiani, A. S., \& Wardhana, A. (2018). Pengaruh Brand Ambassador terhadap Minat Beli Bandung Kunafe Cake. https://www.researchgate.net/publication/328676976_PENGARUH_BRAND_AMBASSADOR_TERHADAP_ MINAT_BELI_BANDUNG_KUNAFE_CAKE.

Ningrum, N. S. (2016). Pengaruh Brand Ambassador Terhadap Minat Beli Konsumen MD Clinic By Lazeta. Bisnis dan Iptek, 141-152.

Oktaviani, L., \& Sutopo. (2014). Analisis Pengaruh Brand Image,Kualitas Produk dan Harga Terhadap Minat Beli Produk Mie Instan Supermie. Diponegoro Journal of Management, 3(4), 1-14.

Prasetya, \& Tri., J. (2004). IImu Budaya Dasar. Jakarta: Rineka Cipta.

Qhusna, N. (2018). Pengembangan Model Pengaruh Culture pada Interface Online Store terhadap Perilaku Repeat Purchase Intention. Institut Teknologi Sepuluh Nopember.

Saputro, A., Sugiharto, D. S., Studi, P., Pemasaran, M., Ekonomi, F., Petra, U. K., \& Siwalankerto, J. (2018). Pengaruh Digital Marketing dan Brand Ambassador dalam Membentuk Brand Identity sebagai Variabel Intervensi terhadap Purchase Intention Pada Produk Markobar. Jurnal Strategi Pemasaran, 5(2), 1-8.

Sen Cece, I. (2015). Pengaruh Brand Origin, Brand Ambassador dan Brand Image Terhadap Minat Beli Sepatu Macbeth di Sogo Galaxy Mall Surabaya. E-Jurnal Manajemen Kinerja, 1(2), 101-110.

Son, S., \& Kijboonchoo, T. (2016). The Impact of Korean Wave on the Purchase Intention of Korean Cosmetics of Thai People in Bangkok and Chonburi, Thailand. PSAKU International Journal of Interdisciplinary Research, 5(2), 76-83. https://doi.org/10.12778/235108618x15452373185705

Sumiati, S. (2020). Dampak Etnosentrime dan Budaya Populer terhadap Sikap Konsumen serta Implikasinya terhadap Minat Beli Konsumen. Jurnal Manajemen Bisnis dan Kewirausahaan, 27-31.

Suparyanto, \& Rosad. (2015). Manajemen Pemasaran. In Media.

Zenas Tjoe, F. (2016). The Effect of Korean Wave on Consumer's Purchase Intention of Korean Cosmetic Products in Indonesia. Korea Open Access Journal, 14(9), 65-72. 